\title{
Light and electron microscopic comparisons of normal hepatocytes and neoplastic hepatocytes of well-differentiated hepatocellular carcinomas in a teleost fish
}

\author{
John A. Couch \\ Environmental Research Laboratory, U.S. Environmental Protection Agency, Gulf Breeze, Florida 32561, USA
}

\begin{abstract}
Well-differentiated hepatocellular carcinomas (HCC's) induced in the sheepshead minnow Cyprinodon variegatus with $\mathrm{N}$-nitrosodiethylamine permitted light microscopical and ultrastructural comparisons of normal hepatocytes and adjacent HCC cells. Normal hepatocytes contained typical organelles with their intracellular distribution similar to that described for other teleosts. These cells revealed a strong compartmentalization of organelles consisting of restricted perinuclear cytoplasm containing rough endoplasmic reticulum (RER) and mitochondria most of the rest of the cell's cytoplasm volume was filled with $\beta$-glycogen particles. Adjacent HCC cells at the border of the neoplasm interdigitated (invaded) between normal hepatocytes and replaced normal hepatocytes close to the HCC edge and adjacent to the bile canaliculi. Within the HCC, cells had little intercellular space between them and atypical bile canaliculi were found occasionally between adjacent hepatocytes. The HCC cells appeared to differ mainly in a quantitative, rather than in a qualitative fashion, and in the distribution of organelles from normal hepatocytes. HCC cells were not compartmentalized; their organelles (RER and mitochondria) were distributed throughout the cytoplasm, and only small amounts of glycogen remained diffusely distributed or in small masses or foci. Mitochondrial intermembrane myelin bodies (MMB's) were found frequently in the HCC cells but less frequently in the normal hepatocytes. Some cells at the edge of the HCCs appeared to be intermediate between inner HCC cells and normal hepatocytes in terms of abundance and distribution of organelles and glycogen. The possible significance of the MMB's and intermediate, edge cells is discussed, as well as the need to better characterize features of well-differentiated hepatic neoplasms in order to assure their proper inclusion in neoplasm incidence/prevalence data in fish carcinogenesis assays and field studies.
\end{abstract}

\section{INTRODUCTION}

Hepatocytes of vertebrate animals, including teleost fishes, have been shown to be major target cell types of toxicants and carcinogenic agents (Couch \& Harshbarger 1985, Motta 1988). Neoplasms originating from the cell types found within the liver of fishes are as varied as they are in mammalian species (Couch \& Courtney 1987, Hinton et al. 1988). In order to identify the cells of origin, and different stages in phenotypic expression, of hepatocellular neoplasms it is necessary to describe, in detail, the cellular features of neoplasms. One of the best approaches is use of experimentally induced neoplasms from stop-studies of model species which permit selection of stages in development of neoplasms or a variety of kinds of neoplasms produced with specific agents on a predictable basis (Couch \& Courtney 1987).

Previous reports have described various hepatocellular neoplasms (both well-differentiated and poorly differentiated) in wild fishes (Smith et al. 1979, May et al. 1987, Myers et al. 1987, Vogelbein et al. 1990) and small aquarium fishes (Ishikawa et al. 1975, Hoover 1984, Couch \& Courtney 1987, Hinton et al. 1988, Bunton 1990), with light microscopy. The morphology and progression of hepatocellular neoplasms appear to vary somewhat within a general framework among different species of vertebrates, e.g. between mammals 
such as rats and teleosts such as salmonids, and even between teleosts species such as salmonids and small aquarium fishes (Hendricks et al. 1984, Hoover 1984, Couch \& Courtney 1987). It is becoming more apparent that high quality light microscopical (LM) studies should be accompanied by, and supported by, electron microscopical (EM) studies in fishes, as well as in mammals, to present more complete and salient cellular characteristics that define specific neoplastic types (Hinton et al. 1984. Hampton et al. 1988, Couch 1991, Nunez et al. 1991).

In an earlier experimental report by Couch \& Courtney (1987), 11 different hepatic lesion types and/or stages were induced by N-nitrosodiethylamine (DENA) in the sheepshead minnow Cyprinodon variegatus. In this earlier study only LM descriptions of the hepatocellular neoplasms were given while other lesions were dealt with in greater detail in subsequent papers. This study represents a more concerted focus on both LM and EM of normal and selected DENAinduced, well-differentiated, neoplastic hepatocyte populations in the fish from the 1987 study. This is the final paper in a series of papers on DENA tumor induction and DENA response potential in the sheepshead minnow (Couch \& Courtney 1987, Hinton et al, 1988, Couch 1990, 1991).

\section{MATERIALS AND METHODS}

Sources of tissues. Hepatic tissues with hepatocellular neoplasms were obtained from sheepshead minnows Cyprinodon variegatus initially exposed for $5 \mathrm{wk}$ to DENA (Sigma Chemical Co.) (57 $\mathrm{mg} \mathrm{l}^{-1}$ ) dissolved in seawater (23\%) (Couch \& Courtney 1987). Following exposure, these fish were held for varying times in clean seawater; samples were taken periodically during the holding period for necropsy, fixation of tissues, and processing for LM and EM study. The samples used in this study were from DENA-exposed sheepshead minnows necropsied and fixed after $62 \mathrm{wk}$ postexposure holding for tumor development. LM slides of liver from control, non-exposed fish from concurrent samples were also studied. Several exposed fish necropsied from the post-62-week samples had discrete, well-differentiated hepatocellular neoplasms as diagnosed by LM study of hematoxylin and eosin $(\mathrm{H} \&$ E) sections. Aliquots of tissues from the livers of these exposed fishes had been fixed at the time of necropsy for EM, and these tissue which included normal liver and hepatocellular carcinoma were used in the EM portion of this study.

Fixation. Liver tissue for LM was fixed in Davidson's fixative, paraffin embedded, sectioned at 5 to $6 \mu \mathrm{m}$, and stained with Harris hematoxylin. Tissues for EM were taken at necropsy, diced to less than $1 \mathrm{~mm}^{3}$ pieces in $3 \%$ glutaraldehyde in Millonig's phosphate buffer, post-fixed in $1 \%$ osmium tetroxide, dehydrated in a graded acetone series, and embedded in Epon 812. Sections (50 to $60 \mathrm{~nm}$ ) were stained with uranyl acetate and lead citrate and examined and photographed with a Zeiss EM10 electron microscope at $60 \mathrm{kV}$.

\section{RESULTS}

\section{Light microscopy of normal and neoplastic tissues and hepatocytes}

Normal parenchyma of liver of both control fish and exposed fish were similar and consisted of clear, vesicular hepatocytes arranged in tightly packed tubules or cords ( 1 to 2 cells wide) similar to those tubules described for other teleosts (Figs. 1a, b, $2 \& 3$ ). These normal hepatocytes possessed large, non-stained cytoplasms (vesicular or clear cells) and eccentrically placed oblong to round nuclei which were surrounded by small cusps of basophilic cytoplasm (Figs. 1a \& 2).

Certain fish from the 62-week sample possessed medium to large well-differentiated $\mathrm{HCC}^{\prime}$ s, some of which occupied up to $50 \%$ of the area of the liver sections. These HCC's possessed both trabecular and compact regions consisting of tightly packed tubules that were from 2 to many cells thick and which demonstrated random, non-polarized cellular patterns (Fig. 4). Most of the HCC cells were similar, in general form, to normal hepatocytes; they did not show extreme departure in shape from normal hepatocytes (e.g. none were spindle shaped; Fig. 2, IC arrow). Tinctorially, the neoplastic hepatocytes (denser cells) were lightly to moderately basophilic in contrast to surrounding, clear, normal hepatocytes. They had ground-glass to coarser granular cytoplasm and displayed both anisocytosis and anisokaryosis (Figs. 2 to 4 ). The membrane profiles (borders) of

Fig. 1. Cyprinodon variegatus. (a) Normal hepatic parenchyma; note the empty appearance of normal hepatocytes (with a bile duct in center) from control fish; (b) portion of well-differentiated hepatocellular carcinoma in exposed liver; note that the edges of the $\mathrm{HCC}$ are not encapsulated, that there is not an inflammatory response, and that $\mathrm{HCC}$ cells invade adjacent clear, normal hepatocyte regions. $\times 400$ 
it.

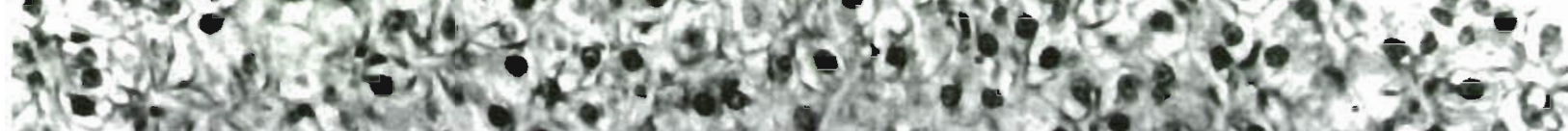
H.

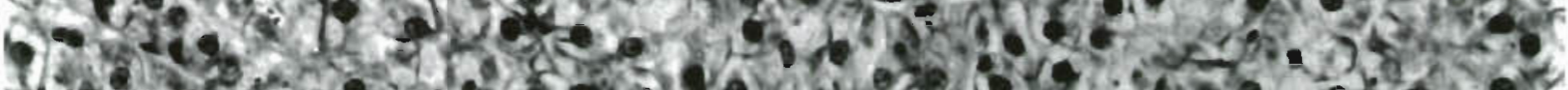

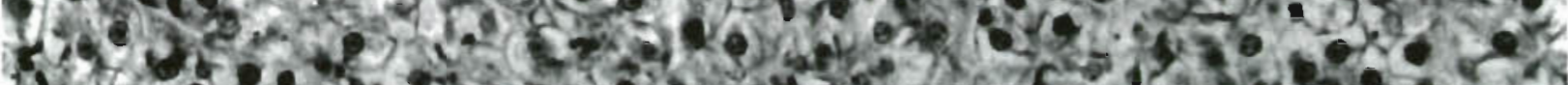

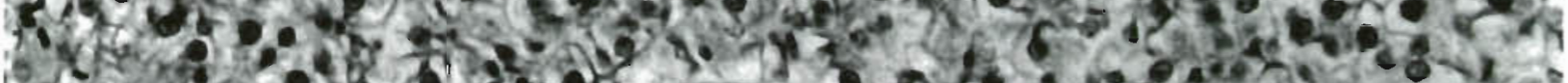
L.

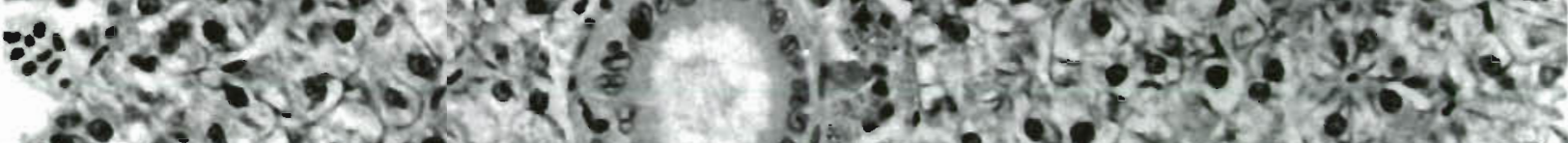

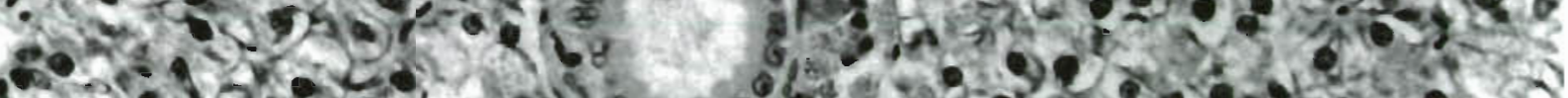
$30 y=3$ of

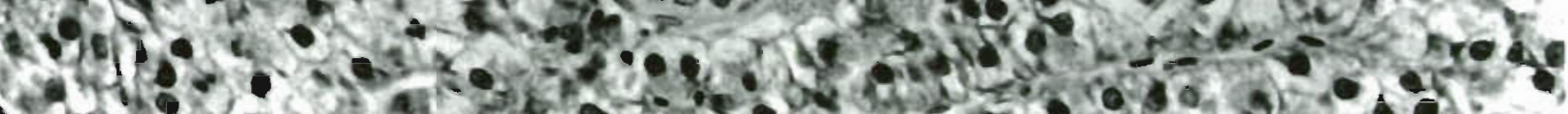

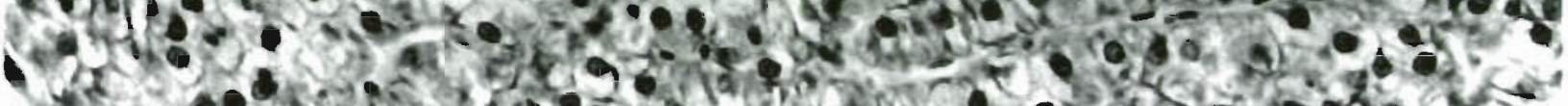

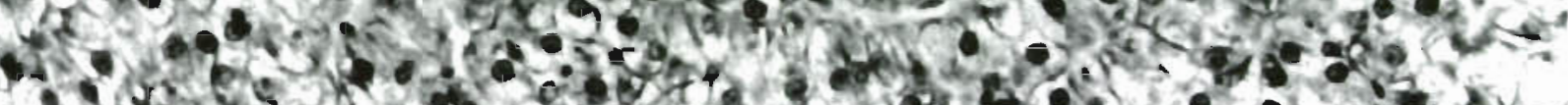

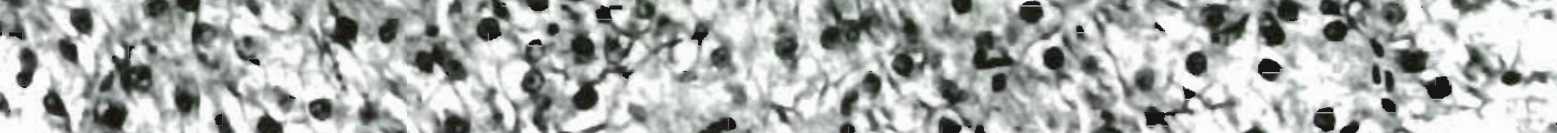

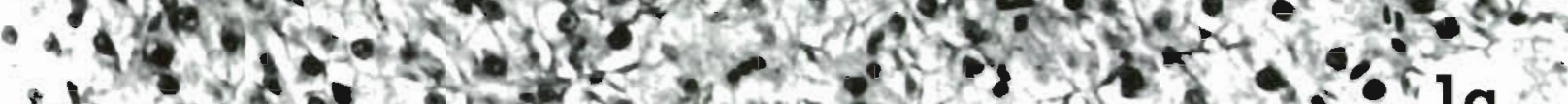

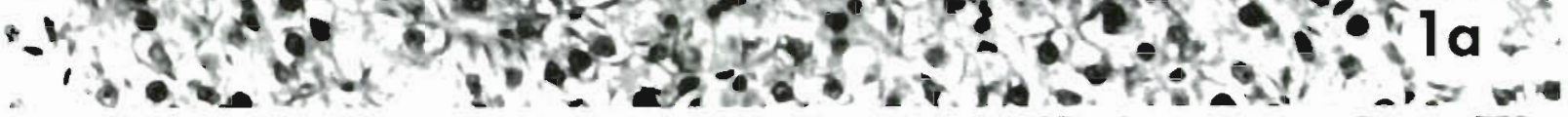

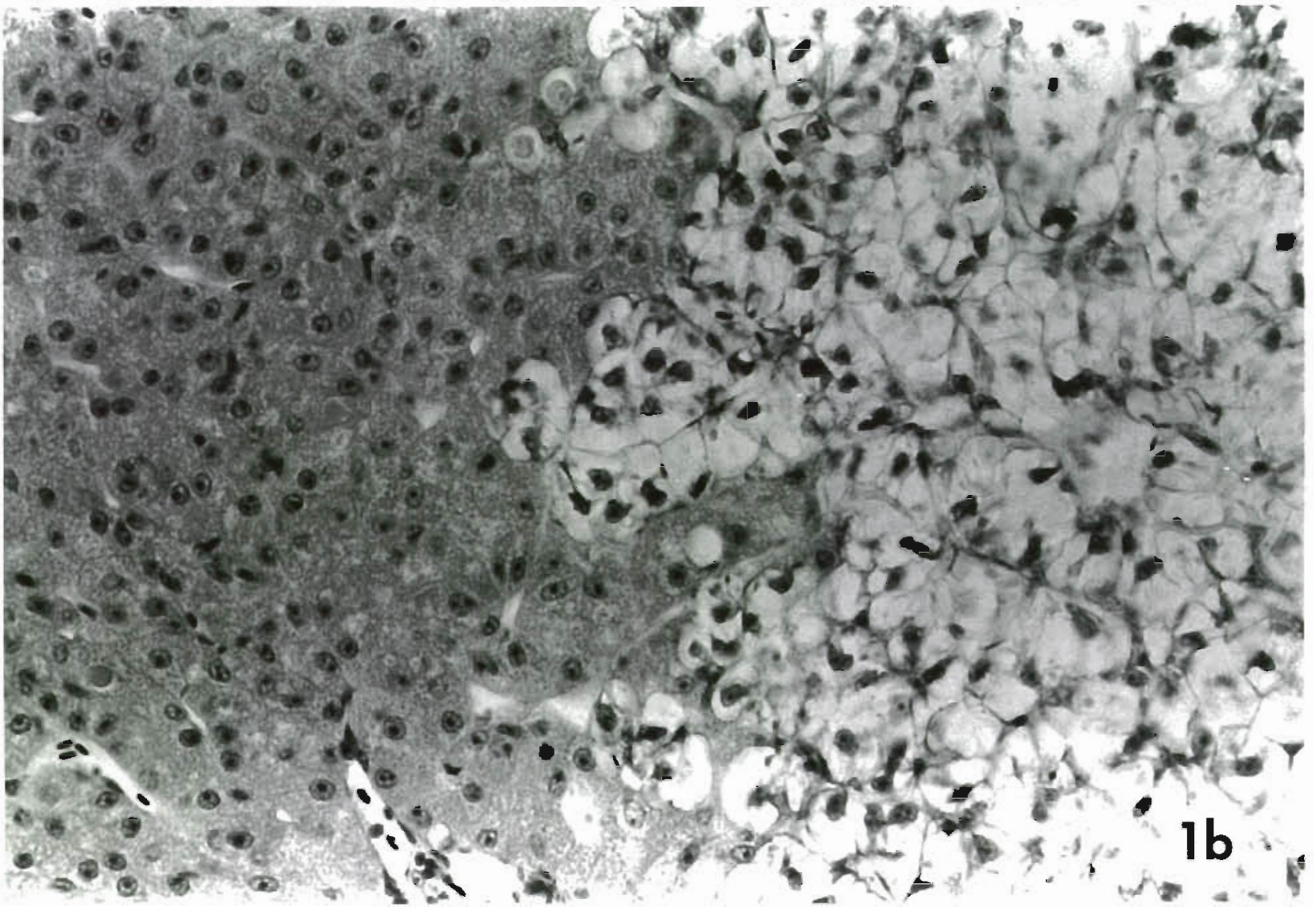



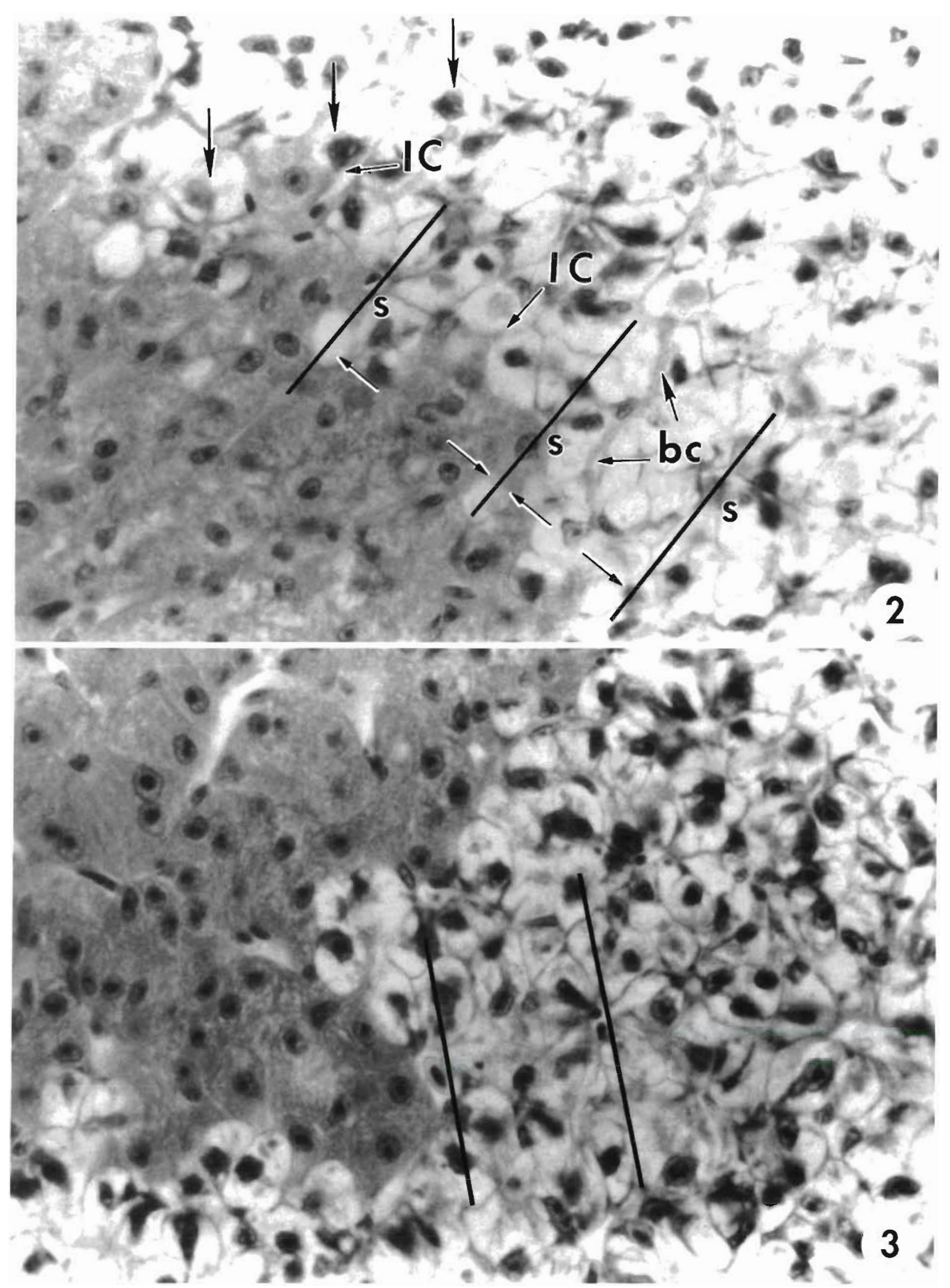


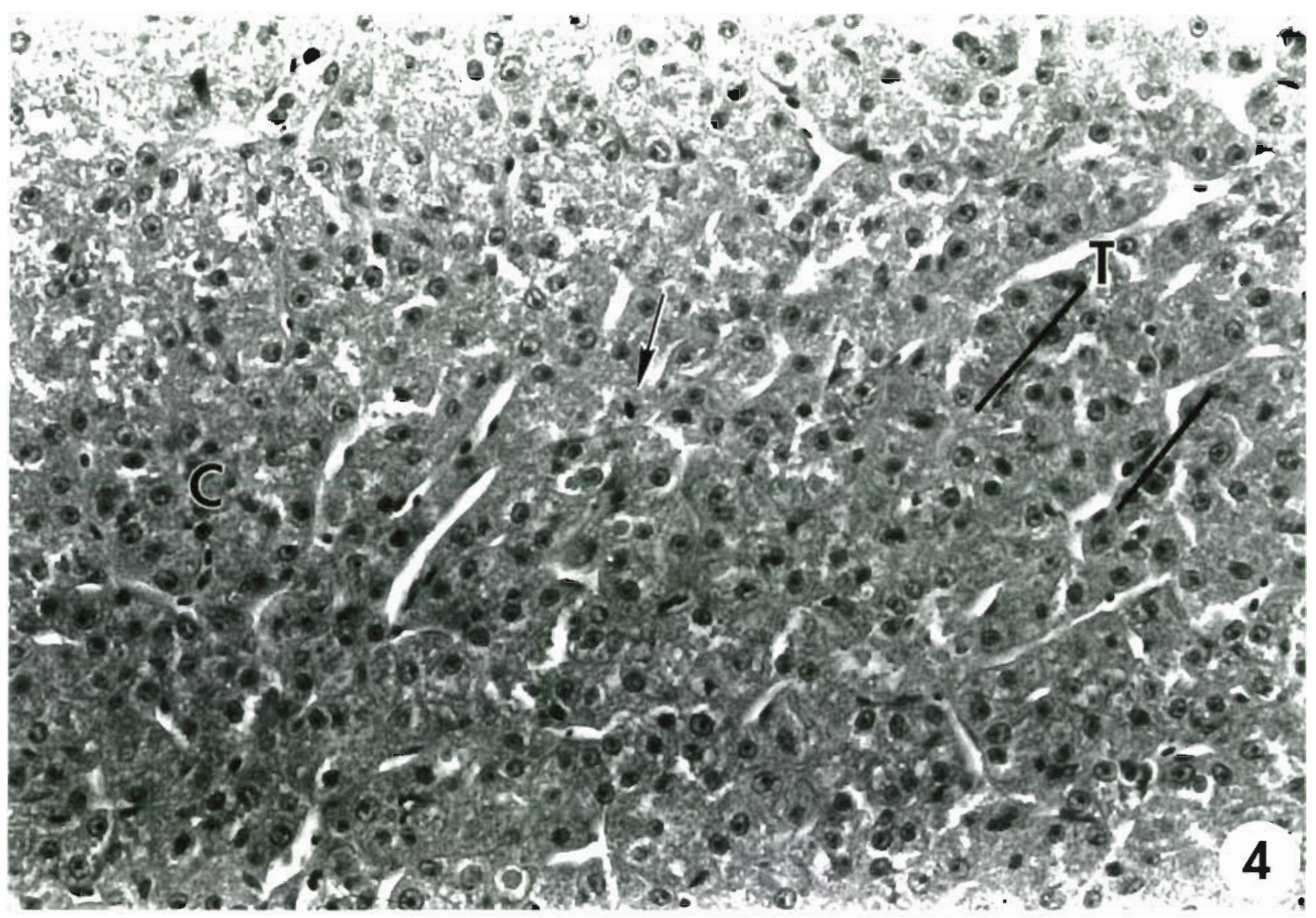

Fig. 4. Cyprinodon variegatus. Interior aspect of well-differentiated $\mathrm{HCC}$; note that some regions of HCC appear more compact (C) as a continuous layer of cells, and others more trabecular ( $T$ ); enlarged tubule with width greater than 2 cells marked with 2 parallel lines; note mitotic figure at center (arrow). $\times 450$

these cells also were more vague and less defined than those of normal hepatocytes and intercellular spaces that were found in more de-differentiated HCC's were absent in the tightly packed tubules (Figs. 2 to 4 ).

An interesting feature of some of the $\mathrm{HCC}$ cells was their highly variable shapes at the borders of the neoplasms and normal parenchyma (Figs. 1 to 3). Certain $\mathrm{HCC}$ cells in these locations appeared to be constituents of tubules shared with adjacent, normal hepatocytes (Figs. 2 \& 10). Their shapes were deformed by pressure exerted by surrounding normal cells, however, suggesting that they might be invasively growing in the space of normal cells (Fig. $2 \mathrm{IC}$; Fig. 3). Normal hepatocytes, however, were only slightly or not compressed along the edges of the HCC (Figs. 2 \& 3). The HCC's did not possess an obvious encompassing or capsular stroma (Figs. 1b, 2, $3 \& 4$ ) and there was no evidence of cellular infiltrate or inflammatory reaction at the edges.

Fig. 2. Cyprinodon variegatus. Higher magnification of edge of well-differentiated HCC; note the perinuclear cusps of basophilic cytoplasm in the adjacent clear, normal hepatocytes (vertical arrows): HCC cell cytoplasm is denser and more homogeneously granular; nuclei of these cells are variable in size, some larger than nuclei in adjacent normal hepatocytes; note that a few HCC cells interdigitate between surrounding normal cells, and at several points have invaded and replaced portions of normal hepatic tubules (the 3 lines and opposing arrows delineate cross-sections of 2 probable tubules); note the lack of any normal tubular arrangement within the $\mathrm{HCC}$; bile canaliculus $(\mathrm{bc}$ ) is seen slightly asymmetrical in one of the tubules, and sinusoids (s) mark the outer borders; lC marks 2 invasion points of HCC cells. $\times 900$

Fig. 3. Cyprinodon variegatus. Peninsula of HCC cells invading normal hepatocyte population from edge of HCC; note the interdigitation of denser HCC cells between normal hepatocytes, suggesting an invasive or replacive behavior in one-quarter of a normal tubule (the 2 parallel lines enclose the adjacent tubule between 2 sinusoids, one of which contains a red blood cell). $\times 900$ 


\section{Electron microscopy of normal and neoplastic hepatocytes}

The normal hepatocyte was charged with homogeneously distributed $\beta$-glycogen particles and lipid droplets that together occupied up to $80 \%$ of their cytoplasms in sections (Figs. 5 \& 6). Thus, their clear or pallid appearance in $\mathrm{H} \& \mathrm{E}$ stained preparatıons apparently resulted from the absence of staining (glycogen) and/or removal during processing (lipid). Cytoplasmic organelles, such as rough endoplasmic reticulum (RER), golgi, and mitochondria, were restrncted to a narrow perinuclear region or to limited areas adjacent to the plasmalemma near a bile canaliculus in these cells
(Figs. $5 \& 6$ ). This pattern of partition or compartmentalization of organelles and other cytoplasmic components such as glycogen and lipids has been described by others for normal hepatocytes of well-fed fish (Hinton \& Pool 1976, Segner \& Braunbeck 1990, Nunez et al. 1991).

Various cytoplasmic organelles were found as follows: cisternae of RER were arranged in typical parallel arrays in the perinuclear cytoplasm, but were not as abundant (Fig. 6) as may be found in normal hepatocytes engaged in high rates of protein synthesis for secretion. Smooth ER was not observed in the scant, condensed perinuclear cytoplasm of these glycogen-charged cells. Golgi cisternae, presumably present, were difficult to find

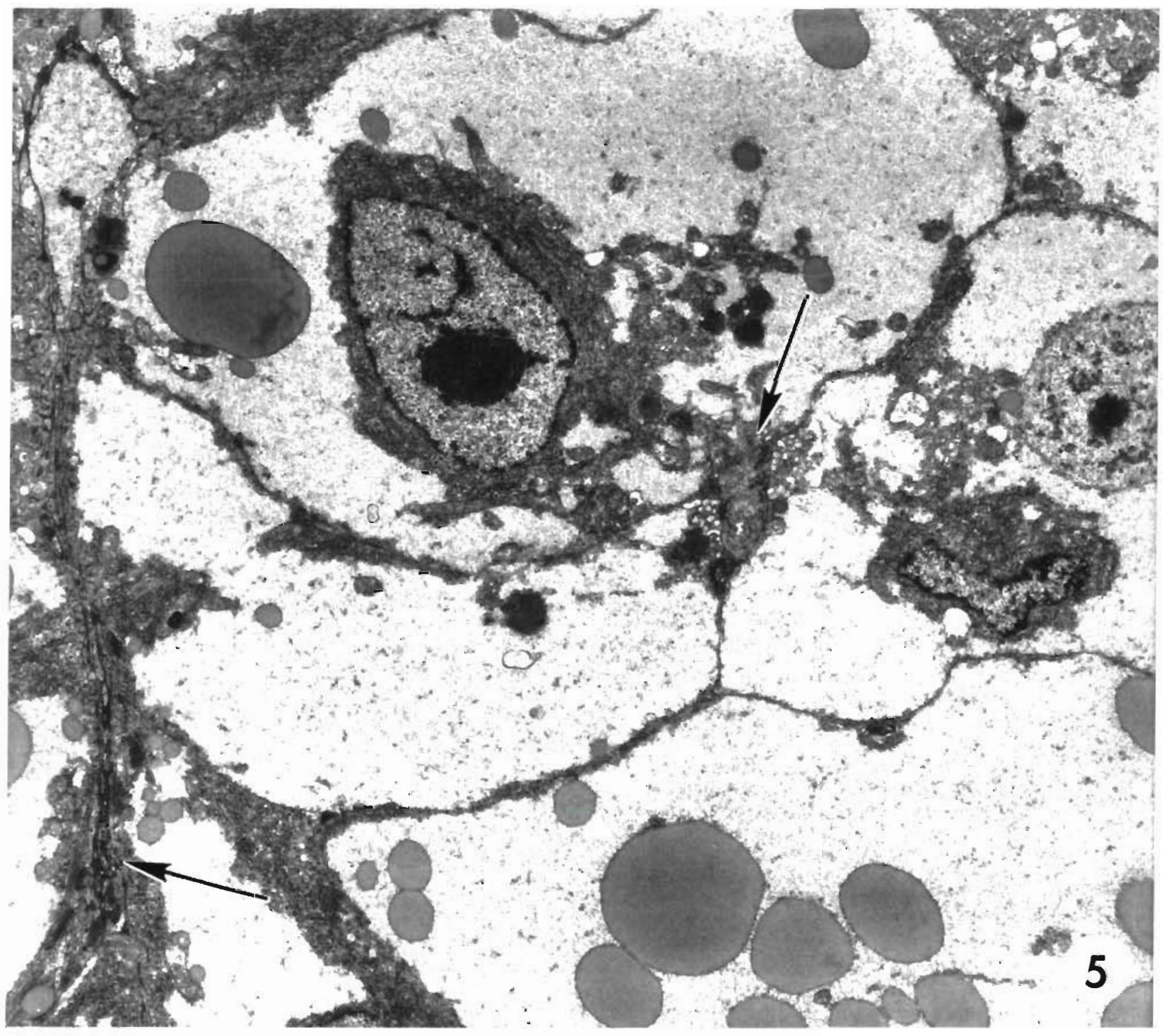

Fig. 5. Cyprnodon variegatus. EM of normal hepatocyte from liver containing well-differentiated HCC's; note perinuclear cytoplasm, extensive compartments of $\beta$-glycogen, a few lipid droplets, and compressed bile canaliculi (arrows). $\times 5000$ 


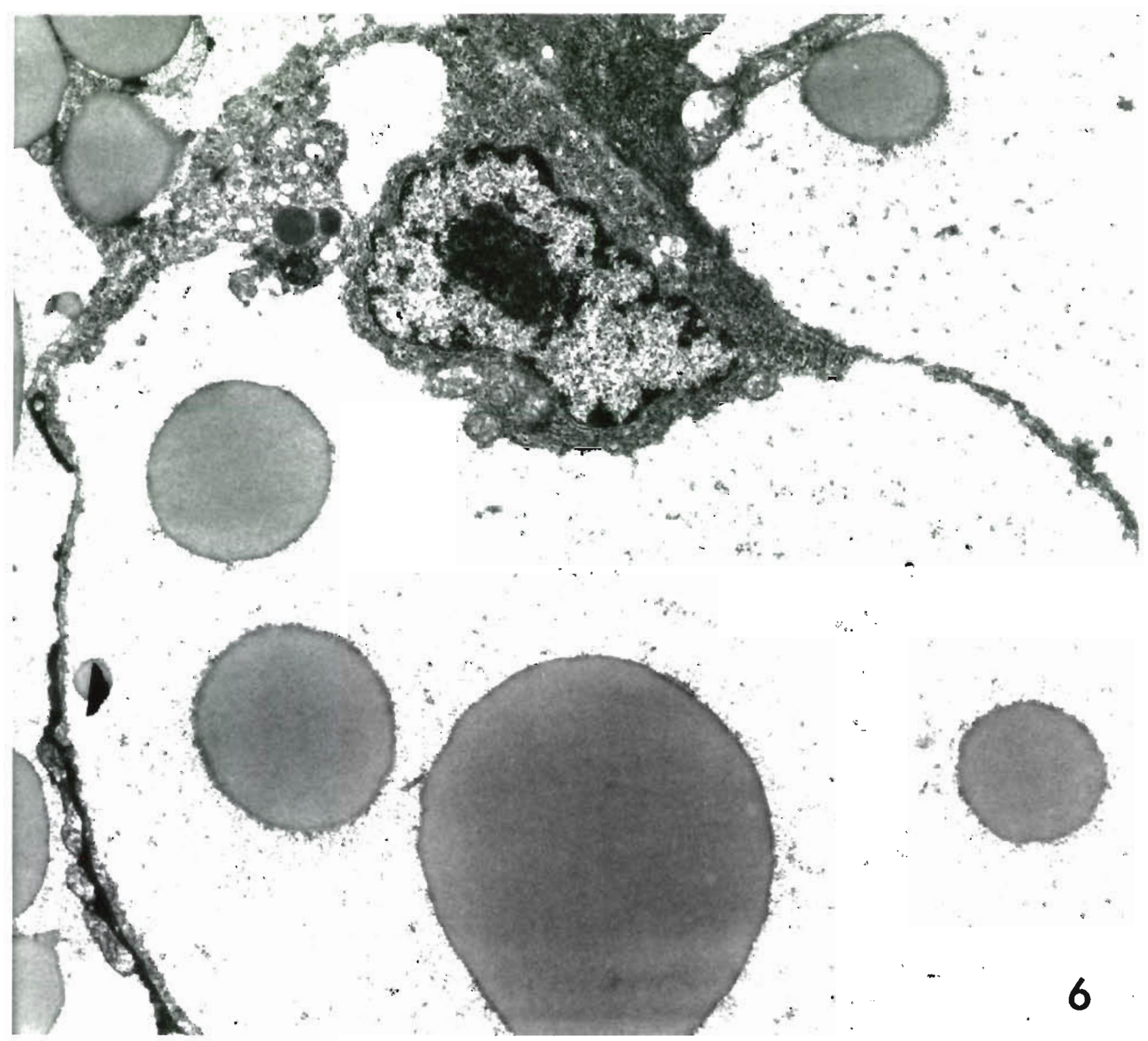

Fig. 6. Cyprinodon variegatus. EM of slightly different aspect of normal hepatocyte near edge of HCC $i$ note extensive glycogen reserves, larger lipid droplets, and a few normal mitochondria in perinuclear cytoplasm. $\times 10000$

because glycogen accumulation occupied much of the hepatocyte section. Relatively few mitochondria were observed (Figs. $5 \& 6$ ). The mitochondria were found in the perinuclear cytoplasm and contained randomly distributed shelf-like cristae, and usually had a less dense, granular matrix internally. The nuclei of normal hepatocytes ranged from round to oval in profile, some were unevenly indented. They usually contained one eccentric nucleolus and a narrow band of marginal heterochromatin (Figs. 5 \& 6).

The parenchymal arrangement of normal hepatocytes appeared typical for teleosts (Fig. 5) at the ultrastructural level but distinct tubular structures were difficult to observe because of immersion fixation. A few intercellular bile canaliculi and highly compressed bile preductules or ductules were identifiable. The latter were recognized because of their microvillous borders and the bile preductular cells that lined them, and their lack of endothelium (Fig. 5). Hepatic sinusoids, circumscribed by spaces of Disse and endothelial cells, were generally reduced in size, perhaps due to compression by adjacent neoplastic cells and glycogen-lipid charge, when compared to hepatocytes. This ultrastructure reflected accurately the general appearance of LM sections as described above. 
The most salıent ultrastructural characteristıc of the HCC hepatocytes was the lack of cytoplasmic compartmentaluzation contrasting with that observed in normal hepatocytes in these fish. The neoplastic hepatocytes making up these well-differentiated HCC's had reduced glycogen and their organelles were widely distributed without clustering in the perinuclear cytoplasm (Fig 7).

Rough ER was found widely in the cytoplasm; RER cisternae generally were not dilated (Figs. 7 \& 8), nor was there much evidence of RER proluferation or accu- mulation in excessive amounts (Fig. 8). Most RER in these cells was closely, even tightly, associated with the abundant mitochondria which were characteristic of these cells (Figs. 7, $8 \& 9$ )

Mitochondria possessed dense, intercristal matrices, and their cristae were frequently arranged in unusual, stacked arrays (Fıgs. $7 \&$ 8). In almost every neoplastic hepatocyte, frequent, distinct, intermembrane vesicles containing membrane fragments and/or myelin bodies, and sometimes small $\beta$-glycogen particles, were formed by the blebbing-out of many outer mito-

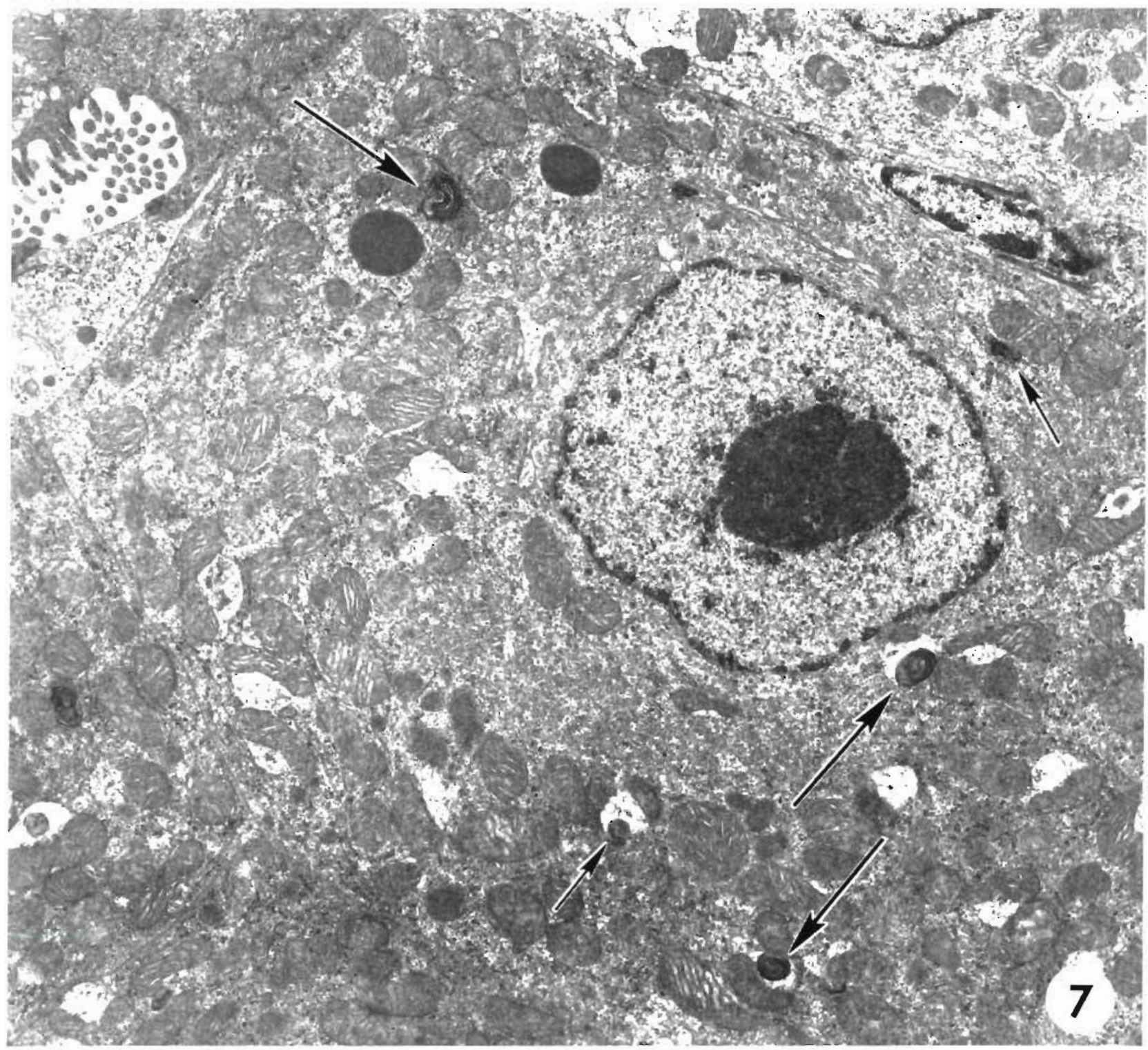

Fig 7 Cyprinodon vanegatus. EM of complete profile of one $\mathrm{HCC}$ cell and portions of other $\mathrm{HCC}$ cells within a welldifferentiated $\mathrm{HCC}$, these cells possess the ultrastructural features characteristıc of $\mathrm{HCC}$ cells observed in this study; note greater electron density of HCC cells in contrast to normal cells in Figs. 5 \& 6 , more general distribution of organelles, and greater numbers of mitochondna with unusual shelf-like cnstae and vesicles in intermembranous spaces of mitochondria, some of which contain MMB's (arrows) $\times 16000$ 


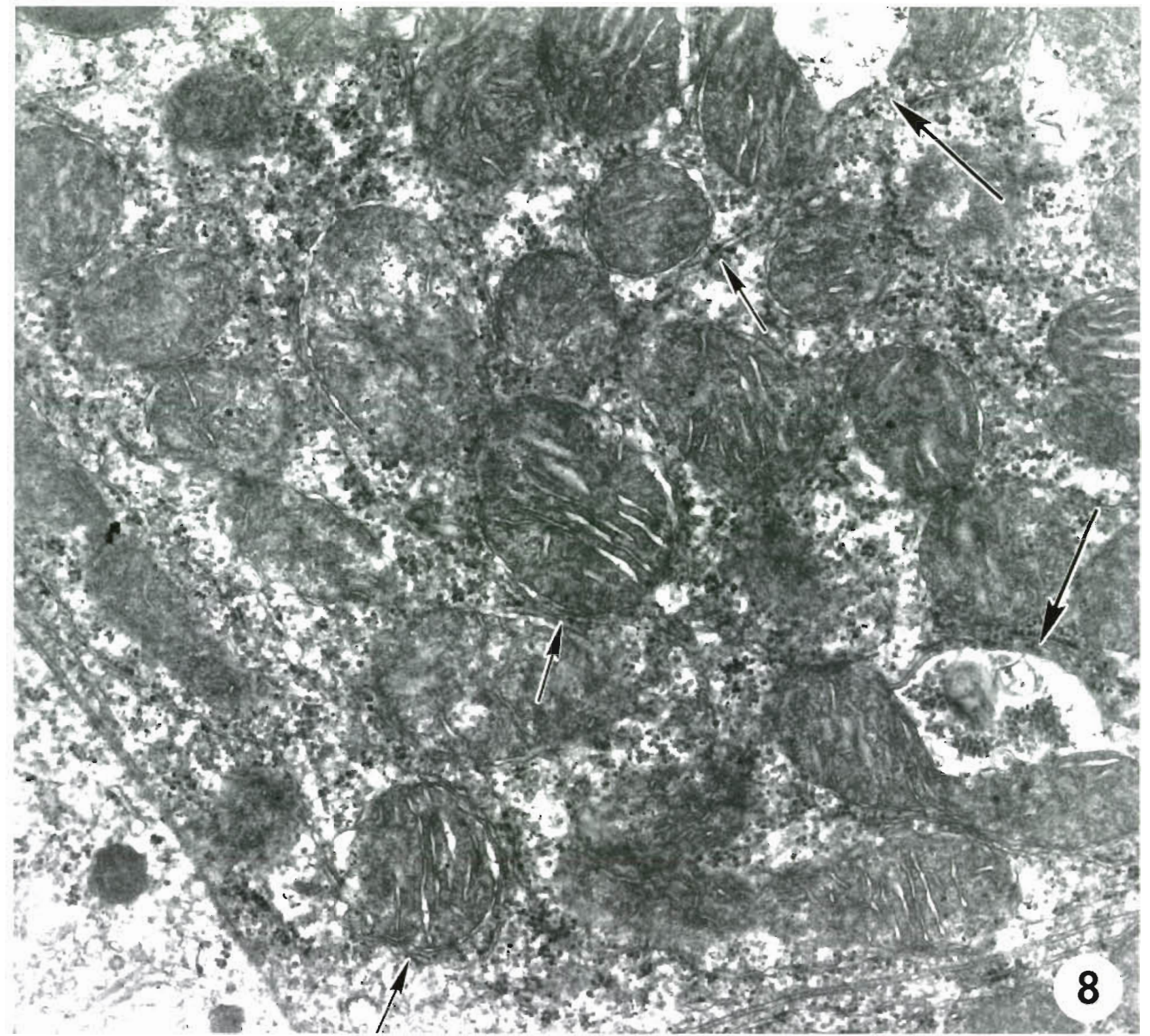

Fig. 8. Cyprinodon variegatus. Higher magnification EM of cytoplasm of $\mathrm{HCC}$ cell; note shelf-like cristae of mitochondria, close association of endoplasmic reticulum, mitochondria (small arrows), and intermembrane vesicle formation in mitochondria with myelin fragments and glycogen particles contained within the vesicles (large arrows). $\times 32000$

chondrial membranes (Figs. 7, 8 \& 9). There appeared to be at least 3 morphological stages in intermembrane, mitochondrial myelin body (MMB) development: (1) dilated mitochondrial outer membrane resulting in a vesicle that contains loosely organized membrane fragments (Figs. 7 \& 8); (2) enlargement of this vesicle and inclusion of more whorled membrane in the form of loosely organized myelin bodies, plus $\beta$-glycogen particles that leaked into the vesicle (Fig. 8); and (3) reduction of vesicle volume against the mitochondrion, with tightly wrapped myelin bodies enclosed (Figs. $7 \&$ 9). The last stage (No. 3) may represent an antemortem deposition of a residuum (myelin body) that may last the remainder of the life of the cell. The MMB appeared to be associated mainly with the HCC cells (compare Figs. 5 \& 6 with Fig. 7); adjacent, normal, glycogen-filled hepatocytes possessed very few MMB's.

Some neoplastic cells had several independent, dense, membrane-bound granular bodies in their cytoplasms (Fig. 7). These could be lysosomes or peroxisomes, but no cytochemical methods were applied to identify them. These bodies were seen less frequently in adjacent, normal hepatocytes. 


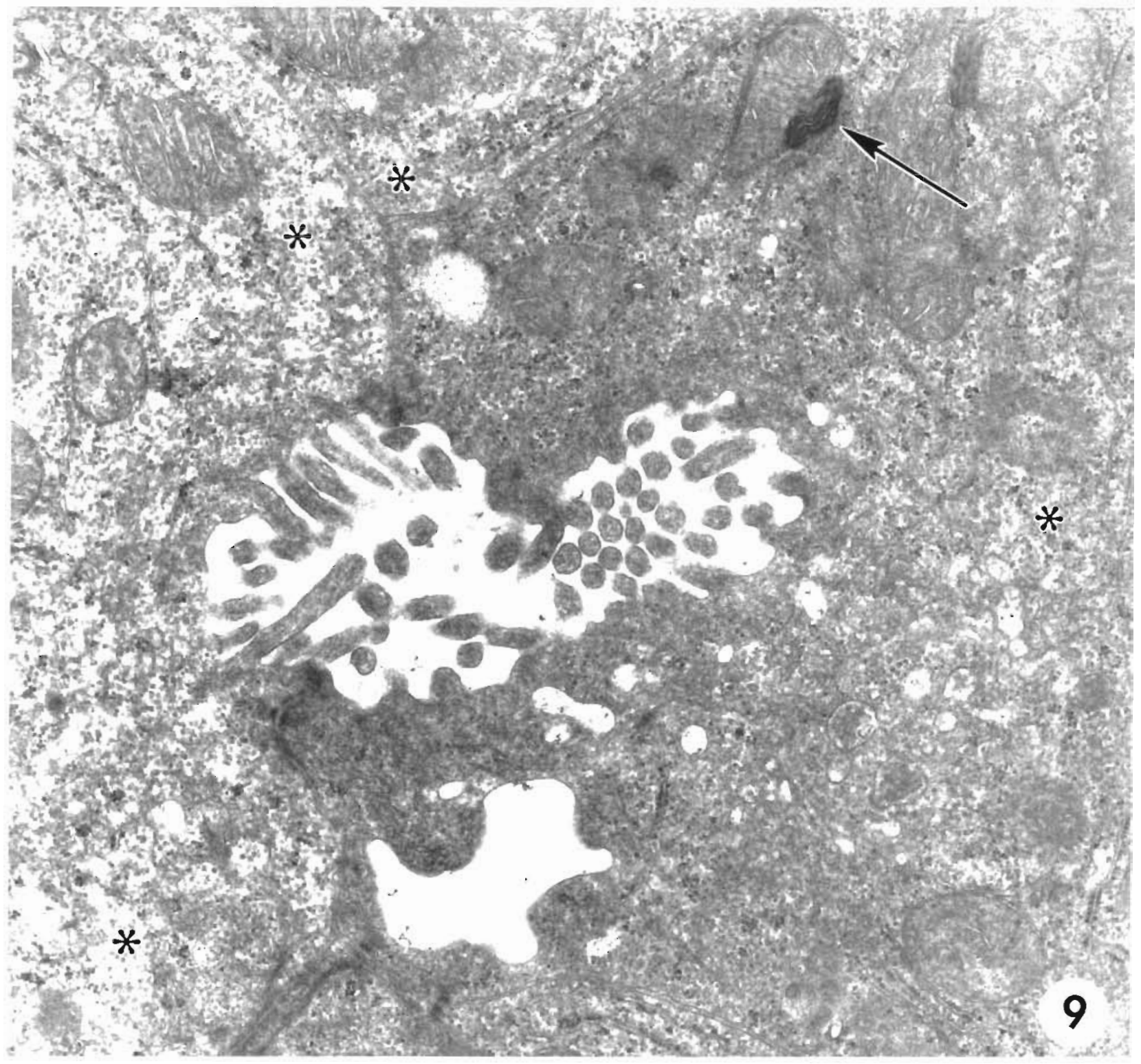

Fig. 9. Cyprinodon variegatus. Junction of $4 \mathrm{HCC}$ cells uncluding abnormal intercellular bile canaliculi, one of which has microvill and surface membrane without microvill, note sparse endoplasmic reticulum closely associated with mitochondna, widely, but thınly, distnbuted glycogen appears among broadly dıstributed organelles in HCC cell (astensks). tıght junctıons are visible at lower center of figure near canaliculı, note fully formed MMB (arrow) in one mitochondrion $\times 25000$

The nuclei of $\mathrm{HCC}$ cells ranged in profile from round to unevenly elongated to severely indented, perhaps more varied in form than in normal hepatocytes. Most possessed a single eccentric or marginal, compact nucleolus and a thın band of marginal heterochromatın lynng on the inner nuclear membrane (Fig. 7).

Within the highly compressed HCC's, there were few gaps or separations between adjacent hepatocytes (Figs. $7 \& 9$ ); contact between the well-differentiated HCC cells appeared comparable to that between normal hepatocytes (Figs. $5 \& 6$ ), and tight junctions or hemidesmosomes, though more widely separated than normal, were still present near canalıcull (Fig 9).

The boundary where the normal, clear hepatocytes met the darker HCC cells was evident with electron microscopy. The ultrastructural features just descnbed charactenzed most normal and $\mathrm{HCC}$ cells at the border (Fig. 10). However, in some contact regions at the edge of the HCC's, a few cells appeared quantitatively intermediate between $\mathrm{HCC}$ cells and normal hepatocytes, 1.e. they contained an intermediate quantity of glycogen, $\mathrm{ml}$ tochondna, and more general distribution of organelles 


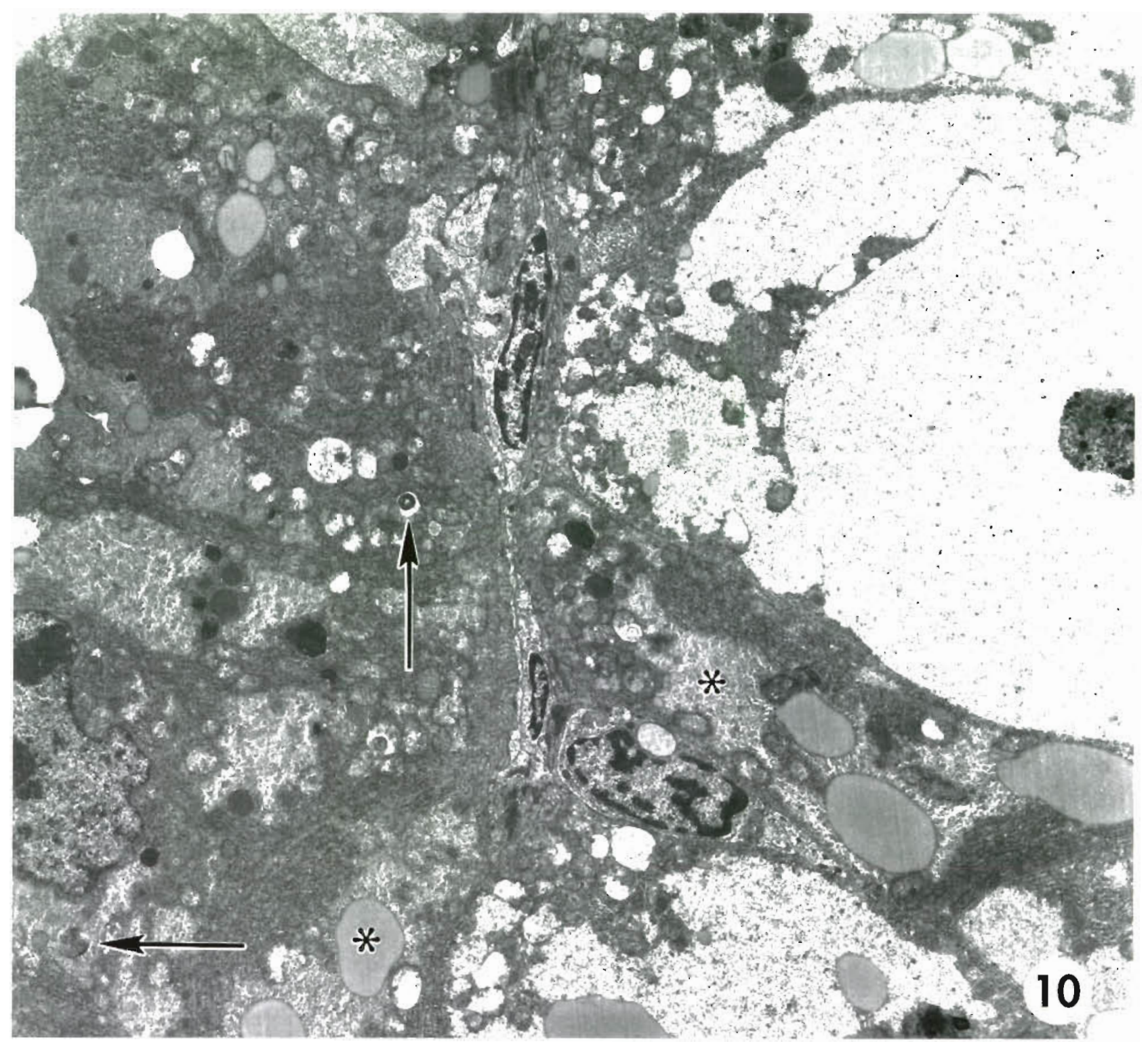

Fig. 10. Cyprinodon variegatus. Edge of HCC that contacts normal hepatocytes; astensks mark possible intermedıate cells and possible remnant adenoma cells that meet and interdigitate between normal, glycogen-charged hepatocytes (see Figs. 2 \& 3 for LM appearance of such edge cells); note highly compressed, probable bile preductule with bile preductular epithelıal cells between denser HCC cells and clearer normal hepatocytes; note abundance of dense figures in HCC cells (probably MMB's) (arrows) $\times 5000$

(Fig. 10). At the ultrastructural level (Fig. 10), these border HCC cells appeared to interdigitate with proximal normal lighter cells, and were deformed by normal cells surrounding them, as revealed with LM (Figs. 2 \& 3). The hepatocytes within the HCC were highly compressed and more homogeneous in profile than the $\mathrm{HCC}$ edge cells. The persistent bile canaliculi observed in the HCC's possessed relatively few microvilli (Figs. $7 \& 9$ ), and in some cases, microvilli were absent on lengths of canalicular membranes (Fig. 9). Sinusoidal and biliary lumina were very narrow, reduced or non-patent (Fig. 10).
Several non-hepatocytic cell types were observed within the HCC. Bile preductular cells (BPC's) were occasionally observed in very compressed areas between hepatocytes, presumably around bile preductules or forming biliary channels (Fig. 10). Possible perisinusoidal cells (PC's) or cells of Ito were observed associated with compressed sinusoids and their spaces of Disse. The latter cells were characterized by both lipid droplets and filamentous material in their cytoplasms (Couch 1991). These non-hepatocyte cells, however, provided no features that contributed to the 
ultrastructural identification of the well-differentiated HCC. Compressed luminal borders with which the presumptive BPC's and PC's were associated possessed microvilli (Fig. 10). Since the only 2 structures in the liver that have microvilli are the biliary channels, including the canaliculus and the bile preductules, and the hepatocyte border in the space of Disse (perisinusoidal space), the probability that the 2 cells types observed were either BPC's or PC's is high even though the compression and deformations of the luminal structures were great, distorting normal cellular relationships often observed in less compressed sinusoids or biliary preductules.

\section{DISCUSSION}

Results of ultrastructural studies that characterized hepatocellular adenomas (HCA's) and relatively distinctly, de-differentiated hepatocellular carcinomas ( $\mathrm{HCC}$ 's) have been published for several species of teleost fishes (Ishikawa et al. 1975, Hinton et al. 1984, Hampton et al. 1988, Nunez et al. 1991). Ultrastructural descriptions of well-differentiated HCC's have not been published, though several reports of LM descriptions of well-differentiated HCC's in fishes have been published (Couch \& Courtney 1987, Vogelbein et al. 1990). This paper concentrates on a comparison of well-differentiated HCC hepatocyte ultrastructure and adjacent normal hepatocyte ultrastructure. Because of the uncertainty of resolving putative welldifferentiated HCC's from early altered foci, adenomas, or variant normal hepatocyte populations with LM alone, further in-depth ultrastructural studies of presumptive well-differentiated $\mathrm{HCC}^{\prime}$ 's were undertaken

The identification of altered hepatocyte populations in this study as well-differentiated HCC's is based on the LM observations that, though the hepatocytes in these populations are minimally deviant (mainly differing in cytoplasmic density and quantitative features) from normal adjacent hepatocytes, they are arranged in patterns of non-polarized growth in engorged tubules of greater than 2 cells width. This cellular arrangement, including relatively frequent mitotic activity in the hepatocytes, strongly indicates that the transition from HCA to HCC has occurred (Nunez et al. 1991) following exposure to DENA. Early altered foci, both basophilic and acidophilic, preceded these lesions in earlier samples (Couch \& Courtney 1987). Further supporting evidence is the finding that in samples of many control or hundreds of wild sheepshead minnows, regardless of age or sex, disparate or abruptly different hepatocyte populations, such as those described here, as $\mathrm{HCC}$ and normal, have not been observed together. Only following the exposure to carcinogens have such different cell populations of such large size been found together in the sheepshead minnow.

Two distinct differences between the subject welldifferentiated HCC's and the poorly differentiated HCC's described by Hampton et al. (1988) and Nunez et al. (1991) and others were: (1) the lack of intercellular spaces between hepatocytes and (2) the relatively more frequent, albeit atypical, bile canaliculi in the sheepshead minnow HCC's. Thus, close cell contact and higher frequency of bile canaliculi, features found in typical rather than atypical patterns, may support diagnosis of well-differentiated $\mathrm{HCC}$ verses relatively de-differentiated HCC.

Specific, cellular ultrastructural findings from past studies (e.g. Hampton et al. 1988, Nunez et al. 1991) on moderately differentiated HCC's in fish in common with present findings were: (1) normal, clear hepatocytes differed from denser $\mathrm{HCC}$ hepatocytes because of differences in quantities of organelles and their distribution; (2) glycogen occurred in larger amounts, and was more widely distributed in normal than in HCC cells (apparently HCC cells undergo more glycogen depletion); this resulted in the compartmentalization of organelles in normal cells, but not in HCC cells in which all organelles are more evenly distributed; (3) fewer mitochondria were found in normal than in HCC cells; this was particularly similar to findings by Hampton et al. (1988) for bullhead catfish HCC's, but is a contrasting finding for that in most mammalian neoplastic cells as reported by Ghadially (1985); an abundance of mitochondria in the fish HCC cells may reflect an attempt to compensate for possible biochemically defective function, or merely to provide greater ATP synthesis to meet increased metabolic energy demands in growing, proliferating cells; (4) HCC cells contained more abundant and more widely dispersed RER than adjacent, normal cells or normal hepatocytes from control specimens; this difference may reflect greater protein synthesis in the blastic $\mathrm{HCC}$ cells than in normal hepatocytes committed to non-growth, storage, or mixed function metabolism.

Only a few qualitative differences between ultrastructure of normal and HCC cells were found in this study. The most conspicuous structures found in $\mathrm{HCC}$ cells, which were largely absent in normal hepatocytes, were the mitochondrial myelin bodies (MMB's). The MMB's were so conspicuous and unique in profiles of HCC cells, in the present study, that they gave the impression of being real antemortem alterations and structural additions to these presumed neoplastic cells. Further indications that the MMB's may be genuine pathological changes in these chemically induced HCC cells are the reports of similar MMB's in 
hepatomas of mammals (Ghadially 1975), in neoplastic hepatocytes in bullhead catfish (Hampton et al. 1988), in toxicant-exposed non-neoplastic fish hepatocytes (Braunbeck \& Völkl 1991), and in cells from eels exposed to mixed toxicants (Spazier et al. 1992). In these reports, as in the present report, the MMB's appear to occupy the intermembranous spaces of hepatocyte mitochondria.

A word of caution is in order, however, if one considers using the $\mathrm{MMB}$ as a possible biomarker or concomitant of hepatocyte neoplastic transformation per se. Ghadially (1985) and Hayat (1989) have pointed out that during prolonged glutaraldehyde fixation for EM, lipids tend to leach out and become hydrated, and then to form myelinoid membrane bodies, particularly associated with nuclei and mitochondria. These bodies could be mistaken by the 'novice' (according to Ghadially 1985) for pathological entities erroneously thought to be induced in the living cell. Liver tissue used in this study was fixed in glutaraldehyde for only 2 to $6 \mathrm{~h}$, not for extended periods. Therefore, it is uncertain whether or not the MMB's described herein are fixation artifacts or are genuine pathological alterations resulting from some toxicant-induced, direct or indirect dysfunction in mitochondrial membrane synthesis as suggested by Spazier et al. (1992).

Such a qualitative alteration as MMB's cannot be related solely to presumed neoplastic transformation in the present study, because even though Hampton et al. (1988) found myelin figures in bullhead HCC cells, Braunbeck \& Völkl (1991) found MMB's in eel nonneoplastic hepatocytes and Spazier et al. (1992) found them in eel spleen cells that were not neoplastic, but which were biochemically altered following exposure to dinitro-o-cresol (DNOC) in both the polluted Rhine River and in laboratory experimental exposures. Therefore, if $\mathrm{MMB}$ induction is not a fixation artifact. but results directly or indirectly from chemically induced cytotoxic effects (e.g. DENA or DNOC exposures), it may represent a useful ultrastructural sign, to be considered with other qualitative signs, in constituting a hepatic ultrastructural syndrome of response to chemical exposure. Further controlled studies are needed to clarify the cause of MMB formation.

Finally, the ultrastructural observation of a few cells at the edge of the HCC's that appear to be intermediate or transitional between HCC and normal hepatocyte needs to be investigated further. At most portions of the border, LM shows a crisp division of the 2 cell populations (Figs. 1b, $2 \& 3$ ). Do those few cells, which seem to be intermediate or transitional (in abundance and distribution of organelles and glycogen), represent invasive $\mathrm{HCC}$ cells, remnants of adenomas or altered foci, or are they cells that, in some yet unknown way, are transformed and recruited from the surrounding normal hepatocyte populations? The simplest explanation is that they are neoplastic cells (perhaps remnant adenoma cells; J. Hendricks pers. comm.).

Both LM and EM in this study (e.g. Figs. 2, 3 \& 10) suggest that neoplastic cells may penetrate or invade normal hepatic parenchyma along biliary routes (bile canaliculi or preductules) and gradually replace normal hepatic tubule cells at the edges of probably slowly growing, well-differentiated HCC's. The lack of inflammatory response at the edges of the HCC's is typical of HCC's described in most fishes to date, particularly in those cases of well-differentiated or moderately differentiated HCC's (Couch \& Courtney 1987, Hampton et al. 1988, Vogelbein et al. 1990, Nunez et al. 1991).

Small fish species, in which neoplasia can be readily induced, are perhaps excellent manipulative models with which to experimentally investigate phenomena at the growing edges of hepatocellular neoplasms.

\section{LITERATURE CITED}

Braunbeck, T., Völkl, A. (1991). Induction of biotransformation in the liver of eel (Anguilla anguilla L.) by sublethal exposure to dinitro-o-cresol: an ultrastructural and biochemical study. Ecotoxical environ. Saf. 21: 109-127

Bunton, T. E. (1990). Histopathology of diethylnitrosamine in the Medaka (Oryzias latipes) following short term exposure. Toxicol. Pathol. 18: 313-323

Couch, J. A. (1990). Pericyte of a teleost fish: ultrastructure, position, and role in neoplasia as revealed by a fish model. Anat. Rec. 228: 7-14

Couch, J. A. (1991). Spongiosis hepatis: chemical induction, pathogenesis, and possible fate in a teleost fish model. Toxicol. Pathol. 19: 237-250

Couch, J. A., Courtney, L. (1987). N-nitrosodiethylamineinduced hepatocarcinogenesis in estuarine sheepshead minnow (Cyprinodon variegatus): neoplasms and related lesions compared with mammalian lesions. J. natl. Cancer Inst. 79: 297-321

Couch, J. A., Harshbarger, J. C. (1985). Effects of carcinogenic agents on aquatic animals: an environmental and experimental overview. Environ. Carcinog. Rev. 3: 63-105

Ghadially, F. N. (1975). Ultrastructural pathology of the cell. Butterworths, Reading, MA, p. 132-133

Ghadially, F. N. (1985). Diagnostic electron microscopy of tumors, 2nd edn. Butterworths, Boston

Hampton, J. A., Klaunig, J. E., Goldblatt, P. J. (1988). Ultrastructure of hepatic tumors in teleosts. In: Motta, P. M. (ed.) Biopathology of the liver: an ultrastructural approach. Kluwer Academic Publishers, Boston, p. 167-175

Hayat, M. A. (1989). Principles and techniques of electron microscopy (biological applications). CRC Press, Boca Raton, p. 34-35

Hendricks, J D., Meyers, T. R., Shelton, D. W. (1984). Histological progression of hepatic neoplasia in rainbow trout (Salmo gairdneri). Natl Cancer Inst. Monogr 65: 321-336

Hinton, D. E., Couch, J. A., Teh, S. J., Courtney, L. A. (1988). Cytological changes during progression of neoplasia in selected fish species. Aquat. Toxicol. 11. 77-112

Hinton, D. E., Lantz, R. C., Hampton, J. A. (1984). Effect of age and exposure to a carcinogen on the structure of the 
Medaka liver: a morphometric study. Natl Cancer Inst. Monogr. 65: 1-409

Hinton, D. E. Pool, C. R. (1976). Ultrastructure of the liver in channel catfish Ictalurus punctatus (Rafinesque). J. Fish Biol. 8: 209-220

Hoover, K. L. (1984). Use of small fish species in carcinogenicity testing. Natl. Cancer Inst. Monogr. 65: 1-409

Ishikawa, T., Shimamine, T., Takayama, S. (1975). Histologic and electron microscopy observations on diethylnitrosamine-induced hepatomas in small aquarium fish (Oryzias latipes). J. natl Cancer Inst. 55: 909-916

May, E. B., Lukacovic, R., King, H., Lipsky, M. M. (1987). Hyperplastic and neoplastic alterations in the livers of white perch (Morone americana) from the Chesapeake Bay. J. natl Cancer Inst. 79: 137-143

Motta, P. M. (ed.) (1988). Biopathology of the liver: an ultrastructural approach. Kluwer Academic Publishers, Boston

Myers, M. S., Rhodes, L. D., McCain, B. B. (1987). Pathologic anatomy and patterns of occurrence of hepatic neoplasms, putative pre-neoplastic lesions, and other idiopathic con-

Responsible Subject Editor: D. E. Hinton, Davis, California, USA ditions in English sole (Paranophrys vetulus) from Puget Sound, Washington. J. natl Cancer Inst. 78: 333-363

Nunez, O., Hendricks, J. D., Duimstra, J R. (1991). Ultrastructure of hepatocellular neoplasms in aflatoxin $\mathrm{B}_{1} \mathrm{AFB}_{1}$ initiated rainbow trout (Oncorhynchus mykiss). Toxicol Pathol. 19: 11-23

Segner, H., Braunbeck, T. (1990). Adaptive changes of liver composition and structure in Golden Ide during winter acclimatization. J. exp. Zool. 255: 171-185

Smith, C. E., Peck, T. H., Klauda, R. J., McLaren, J. B. (1979). Hepatomas in Atlantic tomcod Microgadus tomcod (Walbaum) collected in the Hudson River estuary in New York. J. Fish Dis. 2: 313-319

Spazier, E., Storch, V., Braunbeck, T. (1992). Cytopathology of spleen in eel Anguilla anguilla exposed to a chemical spill in the Rhine River. Dis. aquat. Org. 14: 1-22

Vogelbein, W. K., Fournie, J. W., VanVeld, P. A., Huggett, R. J. (1990). Hepatic neoplasms in the mummichog Fundulus heteroclitus from a creosote-contaminated site. Cancer Res. 50: 5978-5986

Manuscript first received: October 30, 1992 Revised version accepted: February 12, 1993 